\title{
(AI EDAM)
}

\section{ARTIFICIAL INTELLIGENCE FOR ENGINEERING DESIGN, ANALYSIS AND MANUFACTURING}

Volume 6

Number 2

Editor Clive L. Dym

\section{ACADEMIC PRESS}

Harcourt Brace Jovanovich, Publishers

London San Diego New York Boston

Sydney Tokyo Toronto 


\title{
(AI EDAM)
}

\section{Artificial Intelligence for Engineering Design, Analysis and Manufacturing}

\author{
EDITOR \\ CLIVE L. DYM \\ Department of Engineering, Harvey Mudd College, Claremont, CA 91711, U.S.A.
}

\author{
RESEARCH BRIEFS EDITOR \\ MANJULA WALDRON \\ Department of Engineering Graphics, \\ The Ohio State University, \\ Columbus, $\mathrm{OH} 43210$, U.S.A.
}

\author{
BOOK REVIEWS EDITOR \\ DAVID C. BROWN \\ Department of Computer Science, \\ Worcester Polytechnic Institute, \\ Worcester, MA 01609, U.S.A.
}

\section{EDITORIAL BOARD}

Paul R. Cohen, Department of Computer and Information Science, University of Massachusetts, Amherst, MA 01003, U.S.A.

Lynn Conway, College of Engineering, University of Michigan, Ann Arbor, MI 48109, U.S.A.

Johan de Kleer, Intelligent Systems Laboratory, Xerox Palo Alto Research Center, Palo Alto, CA 94304, U.S.A.

John R. Dixon, Department of Mechanical Engineering, University of Massachusetts, Amherst, MA 01003, U.S.A.

S. J. Fenves, Department of Civil Engineering, CarnegieMellon University, Pittsburgh, PA 15213, U.S.A.

Patrick Fitzhorn, Department of Mechanical Engineering, Colorado State University, Fort Collins, CO 80523, U.S.A.

John S. Gero, Department of Architectural Science, University of Sydney, NSW 2006, Australia

R. A. Grupen, Department of Computer and Information Science, University of Massachusetts, Amherst, MA 01003, U.S.A.

John C. Kunz, Center for Integrated Facility Engineering, Stanford University, Stanford, CA 94305, U.S.A.

Jean-Claude Latombe, Department of Computer Science, Stanford University, Stanford, CA 94305, U.S.A.

Victor R. Lesser, Department of Computer and Information Science, University of Massachusetts, Amherst, MA 01003, U.S.A.

Raymond E. Levitt, Department of Civil Engineering, Stanford University, Stanford, CA 94305, U.S.A.
John McDermott, Digital Equipment Corporation, Marlborough, MA 01752, U.S.A.

Sanjay Mittal, Intelligent Systems Laboratory, Xerox Palo Alto Research Center, Palo Alto, CA 94304, U.S.A.

Kiyoshi Niwa, Advanced Research Laboratory, Hitachi Ltd., Tokyo 185, Japan

Panos Papalambros, Department of Mechanical Engineering, University of Michigan, Ann Arbor, MI 48109, U.S.A.

H. Van Dyke Parunak, Industrial Technology Institute, Ann Arbor, MI 48106, U.S.A.

Robert H. Rae, Artificial Intelligence Applications Institute, University of Edinburgh, Edinburgh, U.K.

Daniel R. Rehak, Department of Civil Engineering, Carnegie-Mellon University, Pittsburgh, PA 15213, U.S.A.

Warren Seering, Department of Mechanical Engineering, Massachusetts Institute of Technology, Cambridge, MA 02139, U.S.A.

Melvin K. Simmons, General Electric Company, Schenectady, New York, NY 12301, U.S.A.

J. M. Tenenbaum, Center for Integrated Systems, Stanford University, Stanford, CA 94305, U.S.A.

Arthur W. Westerberg, Carnegie-Mellon University, Pittsburgh, PA 15213, U.S.A.

Graham Winstanley, Information Technology Research Institute, Brighton Polytechnic, Moulescoomb, Brighton BN2 $4 A T, U . K$.

(AI EDAM): ARTIFICIAL INTELLIGENCE FOR ENGINEERING DESIGN, ANALYSIS AND MANUFACTURING: ISSN 0890-0604. Volume 6, 1992, published three times a year by Academic Press at 24-28 Oval Road, London NW1 7DX, U.K. Annual subscription price including postage: 276 U.K. and U.S. \$136 overseas. Personal subscription rates, including postage $\mathbf{8 3 6}$ U.K. and U.S. $\$ 62.00$ overseas. Personal subscription rates are available only on orders placed directly with the publisher and paid for out of personal funds Buyers in Canada should add GST at the current rate of 7\%. Subscription orders should be sent to Academic Press Limited. Foots Cray, Sidcup. Kent DA14 5HP. U.K. (Tel: 081-300-3322). Send notices of changes of address to the publisher at least 6-8 weeks in advance, including both old and new address.

Application to mail at second class postage rate is pending at Jamaica, NY 1143I. U.S.A.

Air freight and mailing in the U.S.A. by Publications Expediting Inc., 200 Meacham Avenue, Elmont, NY 11003, U.S.A

U.S.A. POSTMASTERS: send change of addresses to (AI EDAM): ARTIFICIAL INTELLIGENCE FOR ENGINEERING DESIGN. ANALYSIS AND MANUFACTURING, c/o Publications Expediting, Inc., 200 Meacham Avenue, Elmont, NY 11003, U.S.A.

Printed in U.K.

(C) 1992 Academic Press Limited. The appearance of the code at the bottom of the first page of a paper in this journal indicates the copyright owner's consent that copies of the paper may be made for personal or internal use, or for the personal or internal use of specific clients in the U.S.A. This consent is given on the condition, within the U.S.A., that the copier pay the stated per-copy fee through the Copyright Clearance Center, Inc., 27 Congress Street, Salem, MA 01970, for copying beyond that permitted by sections 107 and 108 of the U.S. Copyright Law. This consent does not extend to other kinds of copying, such as copying for general distribution, for advertising or promotional purposes, for creating new collective works, for resale or for copying or distributing copies outside the U.S.A. 